\title{
A Study on Restraining Sub-synchronous Resonance basic on Flexible AC Transmission Technology
}

\author{
LIU Yan1, 2, a \\ ${ }^{1}$ Skills Training Center of Sichuan electric power company of State Grid, chengdu,610000,China \\ ${ }^{2}$ Sichuan Electric Vocational and Technical College, chengdu, 610000, China \\ aacd.4321@163.com
}

\begin{abstract}
Keywords: Sub-Synchronous Resonance; Synchronous Static Var Compensator; Flexible Ac Power Transmission Technique; Superconducting Magnetic Energy Storage.
\end{abstract}

\begin{abstract}
To increase the transmission capacity of remote high voltage transmission system, the series capacitance compensation of power network is a very economical and effective common measure. But, when electric power system is connected in series with the power transmission system of capacitance compensation and after the system is disturbed under equilibrium state, electric power system may exchange considerable energy with steam turbine generator units with one or several natural frequencies which are lower than synchronizing frequency. Such a phenomenon is called as sub-synchronous resonance (SSR). Under sub-synchronous resonance, inner of generator will create sub-synchronous rotating magnetic field which interacts with synchronous rotating magnetic field forming slip frequency vibration torque. There may be resonance between mechanical and electric systems damaging the axis system of generator. Therefore, it is a worthy topic to study how to restrain the sub-synchronous resonance after compensation of electric power system in series connection.
\end{abstract}

\section{Introduction}

When electric power system is connected in series with capacitance compensation, the system in equilibrium state will be disturbed and electric power system may exchange considerable energy with steam turbine generator units with one or several natural frequencies which are lower than synchronizing frequency. Such a phenomenon is called as sub-synchronous resonance (SSR)[1]. Once sub-synchronous resonance occurs on electric power system, there is a sub-synchronous rotating magnetic field inside the generator. This rotating magnetic field interacts with synchronous rotating magnetic field creating slip frequency vibration torque. Resonance is likely to happen between mechanical and electric systems and damage the axis system of generator[2].

In sub-synchronous resonance, major axis of generator is regarded as some flexibly-connected blocks. Physical nature of sub-synchronous resonance is that the mass blocks in the same disturbed axis are also subjected to relative torsional vibration while taking synchronous rotation. If the system has negative damping to this torsional vibration, the axis of generator may cause sustainable and even enhanced torsional vibration resulting in the fatigue damage of the whole axis.

Wide and profound studies on restraining SSR with FACTS technology have been made. The development of FACTS in China is lagged behind developed countries as a whole. Since the start of study and application of SVC in China from late 1970s, China has accumulated abundant SVC operation experiences and manufacturing technology has become quite mature. At present, there are 6 imported SVCs running in the $500 \mathrm{KV}$ system in mainland China and application in steel enterprises is also widespread. The 20 Mvar STATCOM, as the important science and technology key project of original ministry of electric power and jointly produced by Henan electricity bureau and Tsinghua University, was successfully evaluated in Luoyang on June 27th, 2000. This has enabled China to become the fourth large-capacity STATCOM user in the world and served as an important milestone in the application of FACTS in China.

SMES is a very promising application of superconducting technology in electric system. It is a type of FACTS device integrating superconducting technology and modern electric and electronic 
technology [3]. As it can improve the stability and power quality of power grid, it has become the hotspot of research in recent years [4][5][6]. SMES is a type of fast and efficient energy storing device which can store energy in the superconducting coil in the form of electromagnetic energy. When superconducting magnet is connected to ac network through power electronic converter, it can change the magnitude and phase of output current and thereby obtain the active and reactive power sources which are adjustable in magnitude and direction.

\section{Working Principle and Model of STATCOM}

STATCOM was once named as Advanced Static VAR Generator (ASVG) in China. STATCOM works by the basic principle that self-commutation bridge circuit is connected through electric reactor or in parallel with power grid; by properly adjusting the phase and amplitude of ac side output voltage of bridge circuit, or directly controlling its ac side current, this circuit can absorb or give out required reactive current to embody dynamic reactive power compensation.

As the output waveform of single converter sees a series of square waves, it contains a great proportion of harmonic waves. Assuming that there is a structure composed by multiple converters which are connected in series or parallel, and their output waveforms have certain angle difference, then the final waveforms obtained are close to the staircase waveforms of sine wave, which is the outcome of overlapped output waveforms of converters. This is the multiple technologies for converter. Besides, multiple-technology can also enhance the capacity of STATCOM and thereby play important role in the stability of system. Both voltage-type and current-type converters can embody this. Voltage-type converters should be connected in series while current-type converters should be connected in parallel. The following Fig. 1 is the simple schematic diagram of quadruple of 4 voltage-type converters.

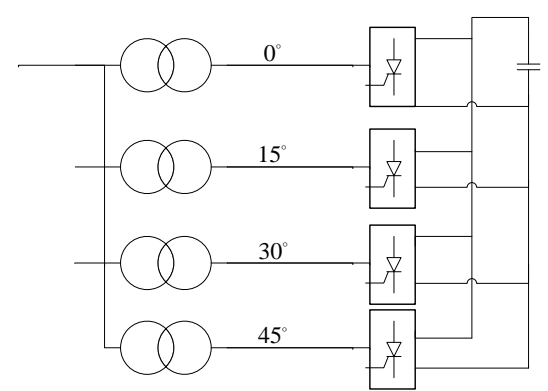

Fig. 1. STATCOM quadruple main circuit diagram

\section{Working principle and model of SMES}

The concept of SMES (superconducting magnetic energy storage) originated from early 1970s [7], the period of oil crisis. As SMES device can directly absorb and release energy to power grid, rather than undergoing an energy exchange process, like electric energy-chemical energy - mechanical energy, it is an efficient and fast energy storing device. It enables very fast energy exchange with power grid at the rate of millisecond magnitude and has been widely applied in electric power system. Compared with the energy storing ways of battery and flywheel, SMES device is highlighted by its high repetitive rate, pollution-free, safety and reliability.

If energy storing coil is made by conventional wires, the magnetic energy stored in coil will be consumed by the resistance of wire. As the direct current resistance of superconductor is zero, the current density is only limited by critical value and higher than common copper conductor by two orders of magnitudes. Therefore, superconducting coil has very high energy storing density and the energy stored will have no loss until it is completely released.

The SMES studied in this paper is a 12-pulse typical inverter whose basic structure is composed by 2 6-pulse 3-phase inverters, one Y $\Delta /$ Y Y connecting transformer and superconducting inductor. To make the active power $P_{s m}$ and reactive power $Q_{s m}$ of SMES independent and controllable in 
four-quadrant, converter usually adopts self-turn-off device, GTO, so that when the firing angle of converter is $\alpha_{1}$ and $\alpha_{2}$, the active and reactive power of SMES is separately [8]:

$$
\begin{aligned}
& P_{s m}=V_{s m 0} I_{s m}\left(\cos \alpha_{1}+\cos \alpha_{2}\right) \\
& Q_{s m}=V_{s m 0} I_{s m}\left(\sin \alpha_{1}+\sin \alpha_{2}\right)
\end{aligned}
$$

\section{MATLAB/SIMULINK Simulation}

This paper studies the IEEE SSR second standard test system. By simulation experiment, we can conclude that when the system adopts $55 \%$ series capacitance compensation, sub-synchronous resonance occurs. The torque $\boldsymbol{T}_{3}$ between low-pressure section A and B axis of prime motor and the torque $T_{2}$ between low-pressure section B and generator shaft is shown in Fig. 2.

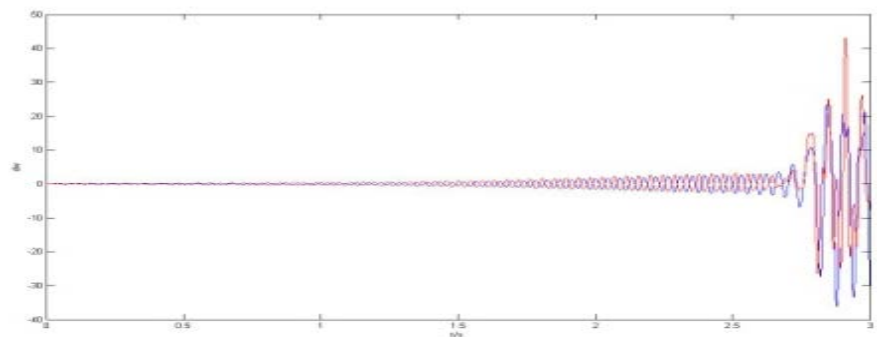

Fig. 2. The torques (P.U) between low-pressure cylinder A and B, and low-pressure section B and generator shaft when sub-synchronous resonance occurs

It can be seen from Fig. 2 that the torque between axes is greater and has significant divergent oscillation, which indicates that sub-synchronous resonance effect occurs on generator. This is just the problem caused by classical series compensation. Fig. 3 shows the voltage (per unit value) of circuit at phase A when sub-synchronous resonance occurs. It can be seen from the fig that when the system has sub-synchronous resonance, the voltage amplitude of circuit increases gradually and the voltage between ends of capacitor also increases rapidly, as shown by Fig. 4. These simulation curves show that sub-synchronous resonance has very serious damage to generator. This is why we are studying how to restrain sub-synchronous resonance.
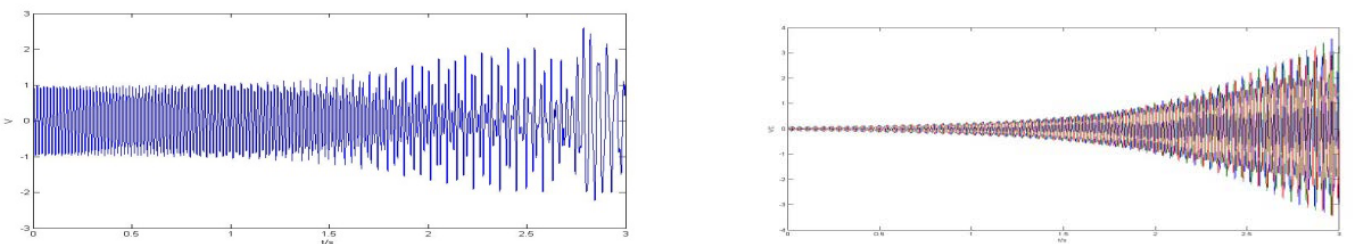

Fig. 3. System A phase voltage of SSR

Fig. 4. Voltage between both ends of capacitors

When STATCOM plan is introduced, the operation of system is shown in Fig. 5-7.

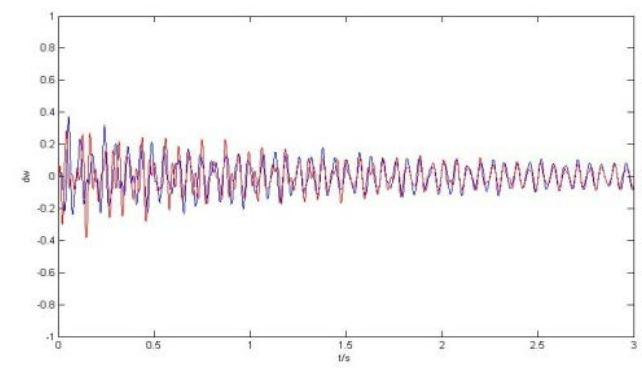

Fig. 5. The torque (P.U) between STATCOM low-pressure cylinder A and B, and the low-pressure section $\mathrm{B}$ and generator axis 


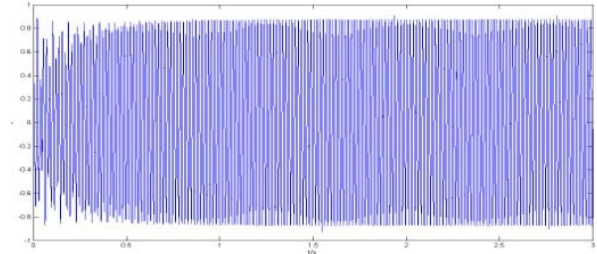

Fig.6. Phase A voltage (P.U) of system containing STATCOM

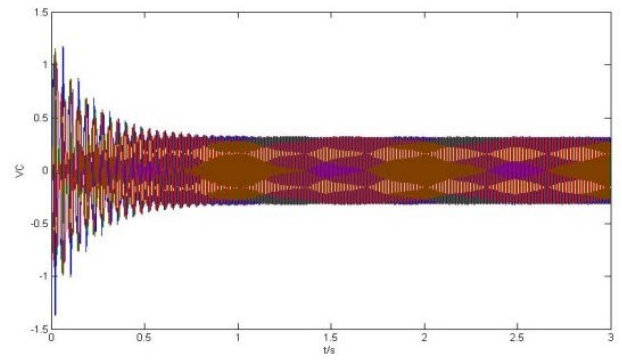

Fig.7. Voltage between both ends of capacitor with STATCOM

By the simulation study on the restraining effect of SMES device on sub-synchronous resonance of electric power system, we can conclude that when the system adopts 55\% series capacitance compensation, there is sub-synchronous resonance, and the torque ${ }^{T_{3}}$ between low-pressure section $\mathrm{A}$ and low-pressure section $\mathrm{B}$ axis, and the torque $T_{2}$ between low-pressure section $\mathrm{B}$ and generator axis is shown in Fig 8.

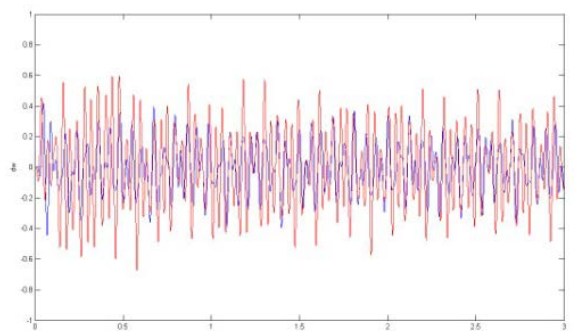

Fig .8. Torque (P.U) between low-pressure cylinder A and B containing SMES, and low-pressure section $\mathrm{B}$ and generator axis

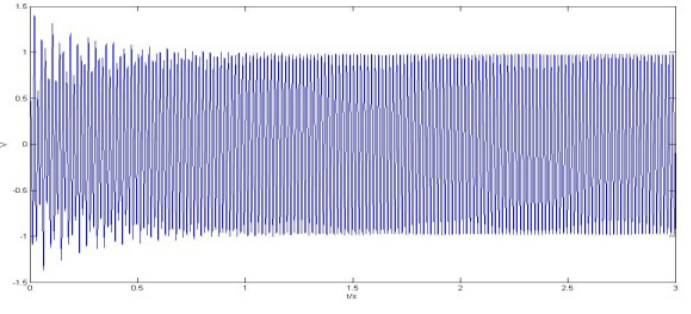

Fig. 9. Phase voltage (P.U) of system A containing SMES

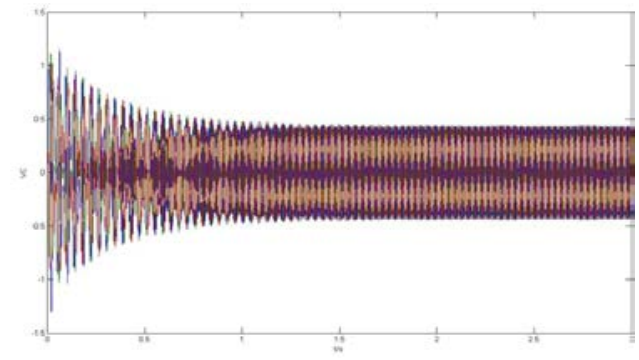

Fig. 10. Voltage between ends of capacitor containing SMES

\section{Conclusion}

It can be seen from Fig 6 and 9 that compared with the curve in Fig 3, when STATCOM and SMES devices are adopted, phase voltage of circuit A becomes stable; it can be seen from Fig 5 and 8 that compared with the curve shown in Fig2, the torque between generator axes becomes stable from the original oscillating and diverging stage. This indicates that after the system introduces STATCOM and SMES plan, sub-synchronous resonance is well-controlled decreasing the probability of torque accident occurring in axis. These simulations validate the effectiveness of damping sub-synchronous resonance control strategy.

Fig 7, 10 and 4 has compared the changes of voltage on capacitors before and after STATCOM and SMES damping sub-synchronous resonance control strategy is introduced. Before the introduction of damping sub-synchronous resonance control strategy, capacitor voltage increases gradually; when damping sub-synchronous resonance control strategy is introduced, capacitor voltage tends to be stable. This has again validated the effectiveness of damping sub-synchronous resonance control strategy 


\section{References}

[1] Zhong Sheng ,Problem caused by adding series compensation devices to EHV transmission system and their solution, Power System Technology, 2004, 28(6) 26-29.

[2] LIU Yan, Analysis of subsynchronous resonance of power system with statcom ,Power System Potection and Cotrol, 2008, 36(20).

[3] Yu Jiang, ZengJianping. Smes in the application of the power system ,Electric power automation equipment, 2000.7, 20(3) 1006-6047.

[4] Li Qun, Xv Dehong, Zheng Jiawei. Carrier-Swapping method to equalize current in a multi-modular current source converter for EMES, Proceedings, 2004, 24(7) 106-111.

[5] Peng Xiaotao, Cheng Shijie, Wang Shaorong. A novel PWM control for current source converter and its application in a SMES, Proceedings, 2006, 60-66.

[6] Wang Fusheng,Liu Xiaoning,Wang Lei, A controller design based on DSP and CPLD for cascaded multilevel convertor, 2006, 26(14) 66-70.

[7] S.Nagaya,H.Hirano, K.Shikimachi, S.Hanai, J.Inagaki, K.Maruyama. Development of MJ-class HTS SMES for Bridging instantaneous Voltage dips, p35.

[8] Rabbani M G, Devotta J B X, Elangovan S1Application of simultaneous active and reactive power modulation of SMES unit under unequala2mode for power system stabilization. IEEE Trans1 on Power Systems , 1999, 14 (2) 547-5521. 